FOUR

WHO'S AFRAID OF

CHARLES SANDERS PEIRCE?

Knocking Some Critical Common Sense into Moral Philosophy

Cornelis de Waal

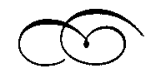

Clear as it seems to me that certain dicta of my conscience are unreasonable, and though I know it may very well be wrong, yet I trust to its authority emphatically rather than to any rationalistic morality. This is the only rational course.

- Charles Sanders Peirce, The Collected Papers of Charles Sanders Peirce

Tn this essay I explore the potential contribution of Peirce's theory of Iscientific inquiry to moral philosophy. After a brief introduction, I outline Peirce's theory of inquiry. Next, I address why Peirce believed that this theory of inquiry is inapplicable to what he called "matters of vital importance," the latter including genuine moral problems. This leaves us in the end with two options: We can try to develop an alternative way of addressing moral problems or we can seek to reconcile moral problems with scientific inquiry as described by Peirce. Though Peirce seems to argue for the former, I argue for the latter.

\title{
The Scientific Method
}

Peirce introduced his theory of scientific inquiry in his Popular Science Monthly series of the late 1870 s as one of four ways of fixing our belief. In the first paper of this series, titled "The Fixation of Belief," Peirce developed a doubt-belief theory that differs quite decidedly from the Cartesian doctrine of universal doubt. By doubting everything he could possibly be 
mistaken about Descartes pretty much stumbled, in the second of his Meditations Concerning First Philosophy, on the ego cogito and declared it the indubitable ground of all knowledge. Peirce radically rejected this approach, as it required Descartes to doubt many things he did not really doubt. In its stead Peirce insisted that doubt can exercise its epistemic function only when it is genuine doubt, not paper doubt. For Peirce, doubt is an actual state of mental discomfort from which we actively seek to free ourselves, and belief is not just a state we have no inclination to change but one to which we even cling with tenacity, as we do not want to fall into mental discomfort. Belief and doubt both spur us into action, but they do so differently. Whereas doubt initiates a struggle, belief acts on the individual rather like a habit or disposition. Having thus distinguished doubt from belief, Peirce subsequently defined inquiry as any struggle that is caused by the irritation of doubt and aims at attaining a state of belief.

Peirce next distinguished four forms that this struggle can take-the scientific method being one of them. However, before looking into these four ways of fixing belief, let's have a quick look at how the doubt-belief model applies to moral issues. As with all beliefs, having certain moral beliefs means that we are conditioned such that were we to be put in a certain kind of situation we would act in certain predisposed ways. So a teenage girl who over the years has internalized her strong pro-life environment and who now finds herself unexpectedly pregnant would have the tendency to reject offhand even the slightest hint that she should consider an abortion. Doubt creeps in where the specifics of the situation undermine rote application of the pro-life beliefs that are so familiar to her. When that happens she is facing a moral problem that calls for some sort of resolution.

As said, Peirce distinguished four ways in which we can seek to regain belief in the face of doubt (note that this belief may be the same as the one we started out with). The first and most primitive way identified by Peirce is that of tenacity: The doubter clings with all her might to her beliefs, ignoring those aspects of the situation that undermine the belief. Being in denial is a classic example of this first method. For social beings like us this method is likely to succeed only in the short term-assuming the facts of the matter even allow us that luxury-as sooner or later we find ourselves confronted with the views of others, and the method does not give us any indication of how to defend our belief against the opposing views of others. Overall, the method of tenacity works best for those moral problems where we have little vested interest, as we will be little affected by any adverse effects and can safely ignore other people's views. The situation is different when we experience firsthand the effects of our beliefs, or when we are forced to account for our actions or explain our views to others.

The second way of fixing belief Peirce calls the method of authority. Here society, in the form of state, church, or otherwise, enforces certain beliefs by manipulating information, or by rewarding those who advocate the accepted belief structure while silencing those who seek to undermine it. Especially within the domain of morality, the method of authority has a long and impressive track record. It is far more powerful and stable than the first, as the opinion of the unvested majority can easily crush the individual with all her struggles. The method of authority allows those who have no vested interest in the problem to decree what should be done. The case of celibate priests asserting how women should behave in marriage, when, with whom, and how to engage in sexual intercourse, or how to raise children, is a clear case in point.

The third way of fixing belief, which Peirce calls the a priori method, secures belief by appealing solely to reason. With this method we try to settle a belief by making it consistent with our general outlook on things. For instance, when applied to the situation of the pregnant teenage girl, her belief would be fixed wholly within the realm of ideas, for instance by making what she should or should not do fit the categorical imperative, by making it fit certain preconceived ideas about the sanctity of life or individual freedom, or by examining her own situation from behind a veil of ignorance. As a way to fix belief, the a priori method is clearly suspect. One need not study philosophy long, or be a particularly astute observer of the human condition, to know that reasoning and rationalizing are often indistinguishable, and that no human evil has gone unrationalized. Even the Nazis had their ethics. ${ }^{2}$

These first three methods are often used in combination. For instance, the fixation of one's belief about abortion may be the outcome of a process in which tenacity, a limited exposure to the views of others, appeals to authority, and preconceived theories, all make their appearance in a fairly stable but by no means static mixture. 
The fourth and last way of fixing belief that Peirce distinguished is the scientific method. Peirce's scientific method presumes that the fixation of belief is not something that is wholly up to us but that there is a world out there to which we must bend. Put differently, the idea that there is an independent reality - things independent of what you, or I, or any group in particular thinks them to be-is key to the scientific method. According to Peirce, each inquirer comes with her biases and idiosyncrasies. However, when the community of investigators becomes sufficiently large, and assuming that each participant is genuinely interested in answering the questions that are being asked, those individual biases and idiosyncrasies are eventually filtered out - the latter often being the products of the first three methods of fixing belief. ${ }^{3}$ As a result we can say that, were an inquiry into a specific question to be engaged in by a sufficiently large community of investigators, then they would in the indefinitely long run arrive at an agreed-upon opinion. Peirce called this the final or ultimate opinion; that is to say, the community of inquirers would reach a permanently fixed belief.

Peirce was careful to observe that we should not look at this final opinion as something that is actually attainable in the near or distant future. Instead he argued that we should engage in inquiry proceeding upon the hope that reaching such an answer is possible, at least in principle. Peirce's independent argument, defended in the Journal of Speculative Philosophy a decade earlier, which states that references to anything absolutely incognizable-such as Locke's substratum or Kant's things in themselves-cannot have any possible explanatory value, further commits him to the view that this final opinion is also the truth. And since its object is per definition independent of what you, or I, or any group in particular thinks it to be, its object is also real. In short, for Peirce, anything that is the object of such a final opinion is real.

That anything that is an object of a final opinion is real seems, at least prima facie, to allow for a moral realism. ${ }^{4}$ When in the indefinite long run-that is, after the issue has been inquired into by countless investigators-the final opinion is reached that incest is wrong, then it would be a real fact that incest is wrong, and the belief that it is so, true. At the same time the personal biases and idiosyncrasies of individual investigators may cause some today to believe that there is no moral objection to incest. Given Peirce's account of the scientific method, those people would be wrong, as their individual beliefs would conflict with the final opinion in the matter. ${ }^{5}$ To put it concisely, the fact that the final opinion would be reached that incest is wrong were the issue to be inquired into long enough makes the practice of incest today immoral, and it does so no matter what one's personal beliefs are or what the mores are of the time and the culture within which one is living. Moreover, it is likely that a certain percentage of our current moral beliefs are identical to those that would be reached at the end of inquiry, making them true (and the ideals expressed in them real) even though we lack the certitude now that they are so. Such a moral realism, moreover, would avoid any need for what John Mackie has called queer objects-objects that do not fit in right with our general picture of the universe. ${ }^{6}$

\section{Matters of Vital Importance}

In his 1898 Cambridge Conference lectures, Peirce, however, takes a radical stance, arguing emphatically that science should stay away from "matters of vital importance," moral problems being among them, thereby denying the validity of a science of ethics. ${ }^{7}$ In the first lecture, "Philosophy and the Conduct of Life," Peirce makes three related points: First, the faculty of reasoning is ill-suited for dealing with matters of vital importance; second, the present state of philosophy is such that any application to such matters is outright irresponsible; and, third, science cannot properly perform its function when matters of vital importance are involved.

First, according to Peirce, our capacity for reasoning is ill-suited for dealing with matters of vital importance. Reasoning in this context is any deliberate train of thought that allows us to use our existing beliefs to remove a particular state of doubt. Since in the current context reasoning pertains to the individual's removal of doubt, Peirce maintains that reasoning "is of its very essence egotistical" $(C P 1.631,1898)$. This clouds the reasoner's ability to distinguish good from bad reasoning, and hence reasoning from rationalization. As Peirce observes, "Men many times fancy that they act from reason when, in point of fact, the reasons they attribute to themselves are nothing but excuses which unconscious instinct invents to satisfy the teasing 'whys' of the ego. The extent of this self delusion is such as to render philosophical rationalism a farce" (ibid). Or, as Thomas Hobbes once famously quipped, reasoning is that faculty that allows us, unlike the brutes, "to multiply one untruth by another." Peirce even states that "ethics, which is reasoning out an explanation of morality, 
is-I will not say immoral, [for] that would be going too far-composed of the very substance of immorality" (CP 1.666, 1898). Were you to study what's going on in the mind of an unprofessional thief, Peirce continues, "you will find that two things characterize him; first, an even more immense conceit in his own reasoning powers than is common, and second, a disposition to reason about the basis of morals" (ibid). It is indeed a familiar fact of life that one can reason in favor of almost anything and that when the stakes in a conclusion increase, the threshold for acceptable reasons tends to lower accordingly. It is far easier to give a convincing argument to someone who already believes the conclusion, than to someone who thinks the conclusion is wholly wrong. Within the United States no moral issue shows this more clearly than that of abortion.

Peirce's second point is essentially an extension of the first. Having observed that the present state of philosophy is such that hardly anything is ever agreed upon-even after all powers of reasoning are employedPeirce continues by saying, "It is precisely because of this utterly unsettled and uncertain condition of philosophy at present, that I regard any practical applications of it to ... conduct as exceedingly dangerous" ( $C P 1.620$, 1898). Given the current state of moral philosophy-and indeed of philosophy in general-and given the earlier discussion about the quirks and limitations of human reasoning, it would be imprudent for anyone to change their beliefs too easily when confronted with the reasoned opposition of others. Given the current state of the science of ethics, Peirce argues, it is simply unwise to ground one's morality on it. At the same time Peirce is careful not to dispose of the baby with the bathwater, allowing that a science of ethics may influence morality, but only "with secular slowness and the most conservative caution" (CP 1.620, 1898).

Peirce's third point is that science cannot properly perform its function, which is to filter out individual biases and idiosyncrasies, in the face of matters of vital importance. The essence of Peirce's conception of science is that the scientist should focus entirely on answering the questions he seeks to address: He should have no preconception of what the answer should be (though, generally, he will have hunches about what it could be); he should be willing to accept the answer, no matter what the answer may be; and he must be willing to drop entire cartloads of beliefs the moment they can no longer be maintained. According to Peirce, it is impossible to live up to this when dealing with matters of vital importance, as generally such issues come with vested interests in what the answer should be-or at least in what the answer may not be-and they generally involve a myriad of ideas that are not up for discussion. Consequently, the muchneeded filtering out of the biases and idiosyncrasies of particular sets of inquirers-which may include the mores of an entire culture-would not be filtered out, and inquiry would come prematurely to a halt.

There is also another, related problem, one that is not directly addressed by Peirce in this opening lecture, and this is the problem that the scientific method is not well adapted to addressing particular problems that require an answer in the short run. This is not a real problem for Peircean moral realism, but it is a problem for anyone who is looking at the scientific method as a potential tool to resolve concrete moral problems. As Peirce is careful to observe, the process through which such a settled opinion is reached is not one of gradual convergence, so that we cannot say that more inquiry will ipso facto land us a better solution or a better argument. As history painfully shows, the general opinion may sway for entire epochs in the wrong direction. However, even if the problem goes beyond the confines of any particular case, say the more general question whether in certain circumstances capital punishment is morally permissible, the short-run interests of investigators are still likely to interfere because of the case's ramifications for issues in which the investigators are vested. Hence, for moral issues short-term interests are likely to continue to interfere over the long run, causing the scientific method to break down. Put differently, even if the investigators have no immediate interest in seeing the answer solved in a particular way, it is unlikely they will be able to reach the level of detachment that Peirce requires for the scientific method to lead to a final, unassailable opinion. To the objection that for any matter of vital importance there will be countless potential investigators to whom the matter isn't vital at all, it can be countered that most of the important moral questions are so pervasive and recurrent that the idea that such a group of investigators can be found, even leaving aside the question of how such a group can be identified, is not a real option.

In sum, on Peirce's account, the ethics of inquiry seems to preclude ethical inquiry. The scientific attitude, which Peirce held to be crucial to science, if not its defining characteristic, appears to break down when we seek to resolve doubt with regard to moral issues.

The view, that the scientific method envisioned by Peirce cannot be made to apply to moral problems, is shared more recently by Bernard 
Williams and Jürgen Habermas. In Ethics and the Limits of Philosophy, Williams takes a Peircean view of scientific inquiry, which, like Peirce, he takes to be an activity that we can justifiably engage in with the hope-if not the expectation-that our answers in the long run will converge to the truth. According to Williams, this is not so for ethical questions. "In the area of the ethical," he writes, "at least at a high level of generality, there is no such coherent hope." And he further adds that should some time in the future such a hope become justifiable, the current explanation given for scientific questions, namely that this convergence is "guided by how things actually are," would still not apply. ${ }^{10}$ Habermas voices similar concerns in Truth and Justification: "Moral validity claims lack the reference to the objective world that is characteristic of claims to truth," and because of that, Habermas continues, they lack the justification-transcendent point of reference that is crucial to the convergence theory. ${ }^{11}$ It seems though that both show themselves to be nominalists with regard to the constraints that are set upon our thought. For Peirce, the way things actually are-or "the objective world of observable states of affairs," as Habermas calls it $^{12}$-is but one way in which our thoughts can be constrained. This is particularly clear in the case of mathematics, which generates truths while caring nothing at all about whether anything in the "objective world of observable states of affairs" corresponds to it or not, and it does so by applying the scientific method.

\section{Peirce's Doctrine of Moral Sentiments}

If science and philosophy are useless, dangerous even, as tools for addressing moral problems, where does that leave us? Peirce seeks the answer in what he calls our moral sentiments-acquired or inherited moral habits of which we have ourselves only a partial cognitive understanding, or even awareness. ${ }^{13}$ In the Cambridge Conference Lectures, for instance, Peirce describes the regnant system of sexual rules as "an instinctive or Sentimental induction summarizing the experience of all our race" ( $C P$ 1.633, 1898). Conscience, Peirce explains elsewhere, "really belongs to the subconscious man, to that part of the soul which is hardly distinct in different individuals, a sort of community-consciousness, or public spirit, not absolutely one and the same in different citizens, and yet not by any means independent in them" $(C P 1.56,1906)$, and he describes moral ideals as "composite photograph[s] of the conscience of the members of the community" ( $C P 1.573,1906) .{ }^{14}$ Put differently, our moral beliefs are not really our private possessions. Rather they are communal affairs in which we partake, something we do mostly unawares. This means that when we come to doubt any such beliefs, that too is not a mere private affair. Moreover, given the precariousness of our reasoning ability, we cannot simply rely on our reasoning powers when trying to remove those doubts. Further, given the current state of moral philosophy, and Peirce's concerns about reasoning more generally, we also better avoid asking the input of professional ethicists. For Peirce, our system of morals is captured in "the traditional wisdom of ages of experience. If a man cuts loose from it, he will become the victim of his passions. It is not safe for him even to reason about it, except in a purely speculative way" (CP 1.50, 1906). Peirce's sentiment seems to be that whereas in science reasoning is a powerful instrument for filtering out personal idiosyncrasies, in ethics it is more likely to introduce them.

With regard to morality, Peirce discerns a dialectic where a rather unstable, conscious, and presumed rational phase is wedged between two relatively stable periods that are driven largely by semiconscious moral sentiments or moral traditions that are taken for granted.

When men begin to rationalize about their conduct, the first effect is to deliver them over to their passions and produce the most frightful demoralization, especially in sexual matters. Thus, among the Greeks, it brought about pæderasty and a precedence of public women over private wives. But ultimately the subconscious part of the soul, being stronger, regains its predominance and insists on setting matters right. Men, then, continue to tell themselves they regulate their conduct by reason; but they learn to look forward and see what conclusions a given method will lead to before they give their adhesion to it. In short, it is no longer the reasoning which determines what the conclusion shall be, but it is the conclusion which determines what the reasoning shall be. This is sham reasoning. $(C P 1.57,1896)$

Hence, in Peirce's view, reasoning about moral issues is all but impossible-it is also not needed. Moral rules and ideals carry with them the authority of many generations. Although these are certainly not infallible, the individual should obey them rather than rely on his own fallible reasoning powers or on that of his peers. Peirce's doctrine of moral sentiments thus implies a moral conservatism: "To be a moral man is to obey the traditional maxims of your community without hesitation or discussion" 
$(C P 1.666,1898) .{ }^{15}$ Subsequent reflections on the normative sciences cause Peirce to put more emphasis on self-determination, arguing that ethics should guide the individual in this self-determination, rather than impose on everyone some alien, preconceived set of rules, and that "what most influences men to self-government is intense disgust with one kind of life and warm admiration for another" ( $E P$ 2:460). In short, ethics is to be grounded in our moral sentiments, where the latter are, especially when we are taking Peirce's conception of the self into account, ${ }^{16}$ some sort of amalgam of individual feelings and social mores.

Returning to the four ways of fixing beliefs that Peirce distinguished in "The Fixation of Belief," we can now conclude that because of the observed problems with reasoning, the a priori method is the least responsible way for dealing with moral issues. Reasoning all too quickly becomes a sham, its powers used for rationalization. For Peirce, because of his doctrine of moral sentiments and his weariness regarding our ability to reason in the face of issues of vital importance, the most responsible way for fixing our moral beliefs seems to be a combination of the methods of authority and tenacity. Finally, the scientific method seems to be favored by neither moral philosophers nor Peirce.

\section{Some Problems with Moral Sentiments}

There are, though, some problems with Peirce's doctrine of moral sentiments. For instance, when he gives some examples of moral sentiments, Peirce clearly betrays a provincial mind. "The mental qualities we most admire in all human beings except our several selves," he writes, "are the maiden's delicacy, the mother's devotion, manly courage, and other inheritances that have come to us from the biped who did not yet speak" ( $C P 1.627,1898)$. Surely not a list we would give now, and most likely one that was even suspect in Peirce's own day. It seems that Peirce is taking some good old-fashioned late nineteenth-century values and giving them an eternal air.

We can even go a step further. It is quite easy to find some historically prevalent moral sentiments that, although most discerning humans reject them, are still very much alive today. Xenophobia and racism are obvious examples. The prudence of xenophobia is no doubt as old as the prohibition against incest. ${ }^{17}$ So what are such discerning people to do, especially when they are a minority? ${ }^{18}$ One could argue that Peirce, careful to prevent morality from derailing, is too accepting of existing moral sentiments and practices. It seems that in the end the only way for us to address existing strong moral sentiments we disapprove of is through reason.

An altogether different problem is that even if Peirce's argument were to work for a number of moral issues for which the dust settled many eons ago, such as incest, ${ }^{19}$ there are countless other issues, and more interesting ones at that, for which there exist competing moral sentiments (as with abortion), where our moral sentiments fall short (as with newly emerging issues such as stem-cell research or genetic manipulation), or with issues that are far too intricate for a blunt instrument like our moral sentiments (as with the issue of digital privacy). To this we can add that most societies today have become social, cultural, and ethnic melting pots, so that even where the issues are not new, traditional values only go so far. In sum, in many cases, if not the majority, we cannot simply rely on our moral intuitions.

For Peirce, however, there is something going on at a deeper level as well, and this is that reasoning, especially when applied to moral issues, ultimately depends on sentiment. As is well known, Peirce distinguished three types of reasoning: deduction, induction, and abduction. Deduction, however, cannot tell us anything new; it can only bring clarity to what we profess to know already. Induction, Peirce argues, doesn't apply to cases of vital importance but is only applicable to situations "where we have, like an insurance company, an endless multitude of insignificant risks" (CP 1.630, 1898). Hence, what we are left with is abduction, which, for Peirce, in the end comes down to our instinct of guessing right ... of us seeing il lume naturale.

Now if moral problems are ultimately decided by instinct, or moral sentiment, is there indeed a role left for reasoning? Why not rely on instinct alone? To address this question the medieval distinction between logica utens and logica docens-one Peirce frequently drew on-may be of help. Peirce, who is writing after Darwin, has a naturalistic take on our ability to reason. Far from being instilled ready-made from on high, it is a natural accomplishment that is grounded within our problem-solving activity and the problem-solving activity of countless generations that came before us, the latter extending all the way back to homo erectus and beyond. This has several implications for how Peirce understands reason. First, reason is not eternal or unchanging but develops over time (and is still developing). Second, since our ability to reason is a product of our 
interaction with-or better, our adaptation to--the universe, our capacity to reason is not a divine light that shines through us, but a reflection of the order of the universe. Put differently, for Peirce, the universe is itself reasonable, and our faculty of reasoning is a reflection of that. Third, since reasoning is grounded in our practical dealings with the world, it is not clear how well it fares when we apply it to subjects that are very remote from this, for instance, when we reason about subatomic particles, multiple galaxies, an omniscient god, or infinite numbers.

Peirce's naturalistic account of reason affects how he sees the relation between reason and instinct. Whereas traditionally reason was considered superior to instinct, Peirce takes the opposite view. Like reason, instinct is a product of the individual's interaction with the environment and as such it is a reflection of the reasonableness of the universe. $\mathrm{He}$ further holds that instinct is subtler and less prone to error than reason is. In fact, reason's sole advantage over instinct, Peirce observes, is that it is reflective: "There is reasoning that reason itself condemns" ( $R$ 832:2), and the distinction between good and bad reasoning lies precisely therein. Instincts can fail, as when a turtle hides in his shell when a car approaches, but they cannot correct themselves. In contrast to instinct, reasoning is thus subject to self-control. Consequently, Peirce defines reasoning in Baldwin's Dictionary as "a process in which the reasoner is conscious that a judgment, the conclusion, is determined by other judgment or judgments, the premises, according to a general habit of thought, which he may not be able precisely to formulate, but which he approves as conducive to true knowledge." 20 The totality of these habits, which are directive, subject to self-control, and approved of by the reasoner, constitutes a rudimentary science of logic that Peirce, following the medievals, calls our logica utens. This logica utens is a rather haphazardly formed but seasoned grab bag of modes of inference. This opens up the possibility of, and even the need for, a systematic study of this logica utens. Still following the medievals, Peirce names the latter logica docens. ${ }^{21}$ The question then becomes whether our natural logic suffices in the face of moral problems, or whether it needs to be supplemented by a study of the various rules of inference-in this case, moral theories explaining the what and the why-to prevent our natural reasoning abilities from leading us astray. It seems, however, that the problem with human reasoning discussed earlier cuts across this distinction. In the face of issues of vital importance we can trust neither logica utens nor logica docens, and it may be argued that it is often our attempts to correct our logica utens through a logica docens that leads us in the wrong direction.

In a way it might be better to speak of ethica utens and ethica docens. Although, as far as I can tell, Peirce never used these terms, they match his general outlook. Ethica utens would refer to the moral beliefs and attitudes that we have internalized in the course of our lives, often without really knowing where they came from or why we maintain them, and which form the often only partially articulated sets of rules and beliefs we employ in normal circumstances to evaluate the views and actions of ourselves and others. Hence, this ethica utens, though it includes our moral sentiments, embraces much more than just them alone. Among other things it includes the values we have been brought up with and our exposure to moral problems, the latter including our exposure to how others deal with moral problems. The views on abortion of the teenage girl I gave at the beginning belong to her ethica utens, and it this ethica utens that forms her primary guide when trying to resolve the moral situation in which she found herself. Ethica docens, in contrast, refers to deliberately developed ethical viewpoints, standards, or theories, to assist us in those cases where we feel or realize that our ethica utens falls short.

Peirce had used his logica utens logicadocens distinction to argue that in metaphysics we need a logica docens on the ground that although our logica utens serves us well in practical affairs, we lose ground when entering the purely speculative realm, and hence are prone to lose direction. Regarding moral problems, however, the situation is rather the reverse. As long as we rely on our ethica utens, without asking questions or second-guessing ourselves, Peirce thinks that we have the best chance of remaining on solid ground, whereas ethica docens is very much capable of steering us in the wrong direction, sometimes with disastrous results. Moreover, even if the prescriptions of ethica docens were correct, paying too close attention to ethica docens would still undermine our morality. Transforming our moral sentiments into abstract moral laws, and subsequently applying them to concrete cases, negatively affects our ability to deal with those cases in very much the same way as the billiard player's shot will be ruined when he seeks to make it by consciously applying the laws of analytical mechanics. ${ }^{22}$ It simply doesn't work.

So where does this all leave us? 


\section{An Apology for an Experiental Ethics}

Because both ethica utens and ethica docens are compromised, because our moral sentiments and our moral theories are compromised, we should return to Peirce's theory of inquiry and see whether we can ground morality within experience, taking into account the accumulated wisdom of others, while being open to the circumstances of the particular situation, as the latter often make a difference.

To examine the applicability of Peirce's theory of inquiry to moral problems, let us look at the case where a terminally ill cancer patient makes the explicit request to stop further medical treatment. Such a request typically involves a number of people who must all somehow come to terms with it by granting the request, denying it, ignoring it, trying to make the patient change her mind, reconciling the problem with their own beliefs, and so on. Generally, the group involved will be mixed: family members, medical personnel, a parish priest, hospital administrators, and so on. In addition, how vested each of them is will also vary, and for various reasons. It may depend on how close they are to the patient but also on certain abstract but deeply ingrained beliefs about the sanctity of life or the right to self-determination, for example, and on vague empirical beliefs like what kind of person the patient is, whether the medical situation is indeed as hopeless as the patient thinks, what procedures must be followed, and so on. So a moral problem like this one comes very naturally with its own community, the members of which have their own idiosyncrasies, so that resolving the moral problem becomes a communal affair in which any of Peirce's four methods of fixating beliefs may be utilized, as well as any mixture of them. As our discussion of Peirce's theory of inquiry showed, applying the scientific method to a concrete case where a patient rejects potentially life-saving medical treatment would ultimately come down to the demand of a free deliberation among people who are all to some degree vested in it, creating for each of them a genuine problem (without requiring that this problem is the same for all). When the scientific method is applied, their deliberation would be among people who are actively seeking a resolution and who are open to listen to each other while acknowledging their fallibility and being willing to have their beliefs challenged.

By incorporating the idiosyncrasies of those who enter the inquiry, the scientific method allows us to remain close to the ethica utens of the community, which includes moral sentiments. This would prevent, as much as is practically feasible and without ignoring our fallibility, that we are too easily lured by an appealing and potentially misleading ethica docens. At the same time, the open exchange with the views of others would prevent, again as much as is practically feasible and without ignoring our fallibility, an all too dogmatic reliance on prevailing ethica utens.

Opting for the scientific method to deal with moral problems implies that we reject ethical theories as being absolute. In ethics there are no "golden rules." A strict adherence to ethical theories, such as utilitarianism or Kantianism, involves an exaggerated reliance on ethica docens. There is, however, a long-standing tradition within moral reasoning-a tradition largely ignored by moral philosophers and hesitatingly embraced by Peirce-that goes by the name of casuistry. ${ }^{23}$ Weary of general abstractions, casuists compare each new case to established cases to determine how to proceed, instead of subsuming the particular case under some general rule as "Thou shall not kill," or "Never use another human being merely as a means." Compared to other approaches in ethics, casuistry comes closest to a dynamic equilibrium of ethica utens and ethica docens, thus allowing more nuanced moral positions that, though fallible, as all our moral positions must be, are more likely to be suited to our moral predicaments.

Recently, casuistry has been revived by Albert Jonsen and Steven Toulmin, who call their approach "New Casuistry." 24 For the casuist, general ethical principles are not the products of theories, hence of a speculative ethica docens, but they are the products of clear cases to which we take them to unambiguously apply, which means that ultimately they hinge on our moral sentiments, or, more precisely, on our ethica utens. For the casuist, it is these clear cases, not theories, that give meaning to general moral principles and that also give them their authority. The rules are derivatives. For instance, we need no intricate argument to prove that a clear case of child abuse is wrong. ${ }^{25}$ We know that child abuse is wrong, not because of certain general principles involving inviolable rights, an abstract calculus of pleasure and pain, or because it violates Kant's categorical imperative, but because of empirically and socially rooted moral sentiments. And these sentiments are not mere subjective emotions; they are an integral part of an ethica utens that has developed itself by means of that rather haphazardly formed but seasoned grab bag of modes of inference that Peirce called our logica utens. This distinguishes this form of 
casuistry from a narrow emotivism. Consequently, the casuist argues that instead of theories what is needed is a taxonomy of cases in which we can situate those situations where our ethica utens breaks down and work from there, in part through a comparative analysis. In this way, casuistry allows us to rely in the moral realm on our logica utens while providing us with a mechanism for dealing with situations where this fails or falls short.

This brings us back to the scientific method, where all involved bring in their ethica utens, as well as their logica utens, and in which both ethica docens and logica docens can be utilized by some to evaluate their own views and those of others, all of this with an eye on how to resolve the specific problem at hand.

Can we then overcome the problems with the scientific method raised earlier? I think we can, at least up to a point. First, regarding the problem that reasoning all too easily comes down to rationalization, or sham reasoning, we can counter that the scientific method is best suited to provide much-needed checks and balances by forcing the discussion into the realm of the community, which forms a veritable marketplace of idiosyncratic views. What is more, since no moral problem is truly unique, there is much to be learned from the experiences of others, so that reasoning is only a part of the picture and comes to play a more subservient role.

Second, Peirce's claim that moral philosophy is in a truly deplorable state does not really affect the applicability of the scientific method to moral issues, as the scientific method does not rely on moral philosophy at all, though it may use existing ethical theories and principles as tools or theoretical frameworks while addressing moral issues. ${ }^{26}$ Again, the communal nature of scientific inquiry may serve to prevent theories from being overextended. Far from maintaining a doctrinal attitude, what is needed is a critical common sense with respect to moral issues. A critical common-sensist approach respects what we commonly take for granted within the domain of morality without accepting it blindly; and it accepts the use of reason when dealing with moral problems, but not indiscriminately. Within the domain of morals reason must tread lightly. It should infuse the debate with reasonableness, not stifle it with an unbending rationality. The critical common-sensist is not only keenly aware of his or her fallibility-both in the realm of sentiments and in the realm of reasoning - but also has a sense when and to what extent the use of reason, or a reliance on sentiment, is appropriate. A Peircean-style new casuistry, where a diverse community of stakeholders together applies the scientific method to genuine moral problems-problems that are not mere academic exercises but that are forced, momentous, and alive to those who experience or study them-is most likely to inspire a critical commonsensist approach to morality. ${ }^{27}$ The same cannot be said of the other three methods for fixing belief.

The third objection raised above is more problematic. It is the demand that the inquirers are truly neutral with respect to the matter they are inquiring into, so they can focus entirely on solving the problems at hand, rather than make their solution match preconceived notions of what should or should not be done. The argument is that it is unlikely that, in contrast to true scientific questions, we will ever find the requisite degree of neutrality when dealing with moral issues. The demand of neutrality, though, could be regarded as a regulative ideal, even if one that is very difficult to live up to, a regulative ideal that becomes operational in the imperative that whenever we are engaged in moral inquiry we should always seek to be as dispassionate as ever and examine each issue from all perspectives we can think of, and not just our own.

The same reply can be given to the related objection that the scientific method is really geared toward the long run and is inapplicable to shortterm problems because any particular group of inquirers may lead itself (and others) astray in significant ways even for centuries to come. Apart from the observation that for some issues, such as the prohibition against incest, such a long run seems already reached, one could counter that the imperative just mentioned, which is essentially Peirce's notion of the scientific attitude, is our best safeguard when dealing with moral issues, as neither our moral sentiments nor our moral reasoning can be trusted.

The previous discussion of Peirce's conception of the scientific method shows that applying it to moral problems can give us a framework that allows us to draw on our moral sentiments and our capability to reason, while staying close to the facts of the matter at hand and bringing in the voices of all parties involved. This prevents us from being too easily swept away by the strength of an emotion or the convincing force of some a priori argument. ${ }^{28}$ What we should expect from the scientific method are habits of thought and action that are rigid enough to act as leading principles while being flexible enough to adapt themselves to circumstances 
that are always different-we should expect habits that reflect reasonableness rather than inviolable reason. Put differently, what we need in the face of moral problems is not more theory but more experience together with a critical common sense to evaluate it, all with the realization that we are fallible beings in the world of action as well as in the world of cognition. The scientific method is most likely to give us that. 